ВЛИЯНИЕ ОСТРОЙ НОРМОВОЛЕМИЧЕСКОЙ ГЕМОДИЛЮЦИИ С АУТОПЛАЗМОТРАНСФУЗИЕЙ НА ПОКАЗАТЕЛИ ГЕМОСТАЗА ПРИ АБДОМИНАЛЬНОМ РОДОРАЗРЕШЕНИИ

\author{
Т. В. Шейкина, О. В. Рогачевский, Т. К. Пучко, Е. М. Шифман \\ Федеральное государственное учреждение Научный центр акушерства, \\ гинекологии и перинатологии им. академика В.И. Кулакова, Москва \\ Министерства здравоохранения и социального развития Российской Федерации
}

\title{
Impact of Acute Normovolemic Hemodilution with Autoplasma Transfusion on Hemostatic Parameters during Abdominal Delivery
}

\author{
T. V. Sheikina, O. V. Rogachevsky, T. K. Puchko, E. M. Shifman
}

Academician V. I. Kulakov Research Center of Obstetrics, Gynecology, and Perinatology,

Ministry of Health and Social Development of the Russian Federation, Moscow

\begin{abstract}
Цель исследования - оценка влияния острой нормоволемической гемодилюции с аутоплазмотрансфузией на показатели системы гемостаза при проведении операции кесарева сечения. Материал и методы. В исследование вошло 119 женщин, которым во время операции кесарева сечения применялась острая нормоволемическая гемодилюция (ОНГ), из них: I группу (основную) составили 62 женщины, которым производилась ОНГ с аутоплазмотрансфузией, во II группу (сравнения) вошли 57 беременных, которым применялась только ОНГ. Изучение системы гемостаза включало исследование плазменного звена, показателей тромбоэластограммы, сосудисто-тромбоцитарного гемостаза и оценки внутрисосудистого тромбообразования. Результаты. Трансфузия заготовленной аутоплазмы (ТА) в качестве гемостатического компонента при проведении ОНГ способствовала развитию умеренной гиперкоагуляции за счет достоверного увеличения концентрации фибриногена на $8 \%$, укорочения $\mathrm{r}+\mathrm{k}$ на $11 \%$ и увеличения ИТП на $12 \%$. На этапе хирургического гемостаза (ХГ) выявлена статистически достоверная разница в результатах между группами, что доказывает наилучший гемостатический эффект применения ОНГ с аутоплазмотрансфузией. Заключение. Проведенное исследование показало, что сочетанное применение ОНГ с аутоплазмотрансфузией способствует стабилизации коагуляционного потенциала крови во время операции кесарева сечения и расширяет возможности проведения ОНГ при интраоперационной кровопотере объемом до 25\% ОЦК. Ключевые слова: операция кесарева сечения; острая нормоволемическая гемодилюция; аутоплазмотрансфузия; коагуляционный потенциал.
\end{abstract}

Objective: to evaluate the impact of acute normovolemic hemodilution (ANH) with autoplasma transfusion on hemostatic parameters during cesarean section. Subjects and methods. The study covered 119 patients in whom ANH was used during cesarean section. Group 1 included 62 women undergoing ANH with autoplasma transfusion; Group 2 (control) comprised 57 pregnant women receiving ANH only. Examination of the hemostatic system involved studies of the plasma link, thromboelastogram readings, vascular platelet hemostasis and evaluation of intravascular thrombogenesis. Results. Transfusion of stored autoplasma as a hemostatic component during ANH favored the development of moderate hypercoagulation due to a significant increase in fibrinogen concentrations by $8 \%, r+k$ shortening by $11 \%$, and a rise in the thrombodynamic potential index by $12 \%$. A statistically significant difference has been found in the results between the groups at a stage of surgical hemostasis, which proves the best hemostatic effect of ANH used with autoplasma transfusion. Conclusion. The study has demonstrated that the combined use of ANH and autoplasma transfusion contributes to the stabilization of the blood coagulation potential during cesarean section and extends the feasibilities of ANH when the volume of intraoperative blood loss is as high as $25 \%$ of the circulating blood volume. Key words: cesarean section, acute normovolemic hemodilution, autoplasma transfusion, coagulation potential.

Проблема профилактики и возмещения акушерских кровотечений остается актуальной до настоящего времени. Кровопотеря при абдоминальном родоразрешении в большинстве случаев составляет 800-1000 мл [1]. В последние годы в акушерской практике все чаще при-

Адрес для корреспонденции (Correspondence to):

Шейкина Татьяна Васильевна

E-mail: Sheikina77@mail.ru меняются современные методы кровесбережения. Одним из таких методов является острая нормоволемическая гемодилюция (ОНГ) с аутогемотрансфузией, которая показана у женщин группы высокого риска по развитию кровотечения во время абдоминального родоразрешения [2]. Однако, по данным литературы, известно, что ОНГ может приводить к снижению коагуляционного потенциала за счет эффекта разведения крови, оказывая влияние на увеличение интраоперационной кровопотери [3, 4]. Для решения задачи стабилизации ге- 
мостатического потенциала крови показано переливание свежезамороженной плазмы (в том числе аутоплазмы), содержащей в естественном сбалансированном состоянии факторы свертывания [5, 6]. В связи с вышеизложенным, представляется интересным проанализировать сочетанное применение ОНГ с аутоплазмотрансфузией при операции кесарева сечения, что позволит компенсировать потерю факторов свертывания и одновременно восстановить глобулярный компонент крови, способствуя адекватному возмещению интраоперационной кровопотери.

Цель исследования - оценка влияния острой нормоволемической гемодилюции с аутоплазмотрансфузией на показатели гемостаза при абдоминальном родоразрешении.

\section{Материал и методы}

В исследование вошло 119 женщин, которым во время операции кесарева сечения применялась ОНГ с аутогемотрансфузией, из них: I группу (основную) составили 62 женщины, которым производилась ОНГ с аутоплазмотрансфузией, во II группу (сравнения) вошли 57 беременных, которым применялась только ОНГ.

У беременных заготовка аутоплазмы производилась методом прерывистого плазмафереза при сроке гестации от 32 до 37 недель. Метод ОНГ с аутогемотрансфузией заключался в предварительном переливании растворов с высоким коллоидно-осмотическим давлением (10\% раствор гидроксиэтилированного крахмала (ГЭК)) в объеме 250 мл за 20 мин до оперативного вмешательства, затем из другой локтевой вены производилась эксфузия аутокрови в пластиковый контейнер с гемоконсервантом из расчета 5-10 мл/кг массы тела с одновременным введением во II группе еще 250 мл 10\% раствора ГЭК, тогда как в I группе сразу после эксфузии производилась трансфузия заготовленной аутоплазмы. Аутогемотрансфузия производилась по достижению хирургического гемостаза.

Объем эксфузируемой аутокрови в обеих группах составил в среднем - 546,32 $\pm 85,68$ мл. Средний объем заготовленной аутоплазмы $-486,74 \pm 72,59$ мл.

Клиническая характеристика обследованных женщин показала, что в исследуемых группах женщины были сопоставимы по возрасту, частоте экстрагенитальных и гинекологических заболеваний, а также течению данной беременности.

Все беременные были родоразрешены операцией кесарева сечения в плановом порядке. Анализ показаний к операции кесарева сечения (КС) показал, что преобладающими были совокупность относительных показаний и осложненная миопия.

Объем кровопотери в группах достоверно не различался $(p>0,05)$, составляя в I группе $-761,7 \pm 97,7$ мл, во II группе $782,7 \pm 86,1$ мл.

Исследование показателей системы гемостаза проводилось до ОНГ, после эксфузии аутокрови, после трансфузии аутоплазмы (ТА), по достижению хирургического гемостаза (ХГ), после реинфузии аутокрови (PA), в 1-е и 5-е сутки послеоперационного периода. Изучение системы гемостаза включало исследование плазменного звена, общей свертываемости крови, показателей тромбоэластограммы, методы исследования сосудисто-тромбоцитарного гемостаза и оценки внутрисосудистого тромбообразования. Методы исследования плазменного звена свертывания крови: определение протромбинового индекса (ПИ), концентрации фибриногена проводилось на автоматическом анализаторе «Behring Coagulation Timer» (Германия) хромогенными и клоттинговыми методами. Исследование общей свертываемости крови: тромбоэластография цельной крови (ТЭГ) проводилась на тромбоэластографе производства Германии. Оценивались параметры хронометричес- кой $(\mathrm{r}+\mathrm{k})$ и структурной (ma, ИТП) коагуляции. Тромбоэластография характеризовалась определением следующих показателей: время тромбопластино- и тромбинообразования $(R)$; время фибринообразования $(K)$; время ретракции сгустка $(S)$; общее время коагуляции $(T)$; максимальная амплитуда $(M A)$. На основании вышеуказанных показателей вычислялись расчетные показатели: 1) эластичность сгустка (Е): E=MA/100-MA; 2) индекс тромбодинамического потенциала (ИТП); ИТП = Е/К. Методы оценки внутрисосудистого тромбообразования: РКМФ (орто-фенантролиновый по Елыкомову и Момоту, этаноловый по Godal и Abildgaard и протаминсульфатный тесты по Niewearowski и Gurevich); Д-димер (наборы «DADE», США). Методы исследования сосудисто-тромбоцитарного гемостаза: подсчет количества циркулирующих тромбоцитов в цельной крови проводился на автоматическом счетчике Cobas Micros 18 «oche».

Полученные в процессе исследования результаты подвергались статистической обработке.

\section{Результаты и обсуждение}

В ходе проведенного исследования у всех женщин перед операцией кесарева сечения до проведения ОНГ имела место хронометрическая и структурная гиперкоагуляция, что является физиологической особенностью коагуляционного состояния накануне родов. Результаты, полученные при исследовании параметров гемостаза у исследуемых женщин, представлены в табл. 1 и 2.

На начальном этапе операции КС после проведения эксфузии аутокрови в обеих группах отмечалось снижение коагуляционного потенциала за счет достоверного снижения концентрации фибриногена в I группе в среднем на $11 \%$, во II группе - на $9 \%$. По данным тромбоэластограммы отмечалось достоверное удлинение показателя $\mathrm{r}+\mathrm{k}$ в I группе в среднем на $10 \%$, во II группе - на 9\% по отношению к исходным данным. После эксфузии аутокрови произошло статистически достоверное уменьшение ИТП в I группе на $11 \%$, во II группе - на 9\%. Количество тромбоцитов достоверно снижалось в обеих группах в среднем на 10\%. Полученные результаты показали, что ОНГ приводит к снижению коагуляционного потенциала крови, однако значения показателей после эксфузии находились в пределах допустимых значений.

После эксфузии аутокрови в I группе производилась трансфузия заготовленной аутоплазмы, которая приводила к развитию умеренной гиперкоагуляции за счет достоверного увеличения концентрации фибриногена на $8 \%$, укорочения АЧТВ с $32,7 \pm 2,2$ до $30,7 \pm 2,4$ сек $(p<0,05)$, уменьшения $\mathrm{r}+\mathrm{k}$ на $11 \%$ и увеличения ИТП на $12 \%$. Таким образом, трансфузия аутоплазмы при проведении ОНГ как гемостатического компонента, приводит к повышению коагуляционного потенциала крови, тогда как во II группе показатели гемостазиограммы на данном этапе достоверно не менялись.

После реинфузии заготовленной аутокрови при сравнении с показателями на момент хирургического гемостаза в I и II группах произошло повышение коагуляционного потенциала, которое выражалось в статистически достоверном увеличении уровня фибриногена в обеих группах (в среднем на 10\%). Достоверное увели- 
Динамика показателей гемостаза при проведении ОНГ с аутоплазмотрансфузией во время операции кесарева сечения

\begin{tabular}{|c|c|c|c|c|c|c|c|c|}
\hline \multirow{2}{*}{$\begin{array}{l}\text { Показатель } \\
\text { в группах }\end{array}$} & \multirow[t]{2}{*}{ Группа } & \multicolumn{7}{|c|}{ Значения показателей на этапах исследования } \\
\hline & & до ОНГ & после ОНГ & после ТА & после ХГ & после РА & 1-е сутки & 5-е сутки \\
\hline \multirow[t]{2}{*}{ Фибриноген, г/л } & I группа & $5,20 \pm 0,86$ & $4,64 \pm 0,74 *$ & $5,01 \pm 0,95^{* *}$ & $4,36 \pm 0,53^{*}$ & $4,53 \pm 0,82 *$ & $5,04 \pm 0,92$ & $5,01 \pm 0,52$ \\
\hline & II группа & $5,18 \pm 0,95$ & $4,56 \pm 0,56^{*}$ & - & $4,01 \pm 0,41^{*}$ & $4,02 \pm 0,34^{*}$ & $4,73 \pm 0,53^{*}$ & $4,68 \pm 0,40^{*}$ \\
\hline \multirow[t]{2}{*}{ АЧТВ, сек } & I группа & $30,4 \pm 1,97$ & $32,3 \pm 1,23^{*}$ & $30,7 \pm 2,43^{* *}$ & $32,5 \pm 1,82$ & $31,5 \pm 1,09$ & $29,6 \pm 1,08$ & $28,7 \pm 1,62$ \\
\hline & II группа & $32,6 \pm 1,74$ & $33,6 \pm 1,18^{*}$ & - & $35,1 \pm 1,41^{*}$ & $35,7 \pm 1,11^{*}$ & $30,2 \pm 1,54$ & $31,5 \pm 1,49$ \\
\hline \multirow[t]{2}{*}{ ПИ, \% } & I группа & $105,9 \pm 1,36$ & $106,6 \pm 1,47$ & $105,2 \pm 1,7$ & $107,3 \pm 1,3$ & $106,1 \pm 1,02$ & $104,9 \pm 1,12$ & $102,9 \pm 1,89$ \\
\hline & II группа & $107,1 \pm 1,71$ & $108,5 \pm 1,66$ & - & $109,6 \pm 1,3$ & $109,2 \pm 1,37$ & $105,8 \pm 1,31$ & $104,4 \pm 1,33$ \\
\hline \multicolumn{9}{|l|}{ Тромбоциты, } \\
\hline \multirow[t]{2}{*}{$\times 10^{9} /$ л } & I группа & $281,3 \pm 62,2$ & $245,3 \pm 55,3^{*}$ & - & $214,7 \pm 24,7^{*}$ & $242,7 \pm 44,7^{*}$ & $217,4 \pm 31,7^{*}$ & $302,9 \pm 38,7$ \\
\hline & II группа & $279,4 \pm 56,8$ & $238,2 \pm 47,2^{*}$ & - & $203,2 \pm 28,2^{*}$ & $228,6 \pm 54,9^{*}$ & $205,3 \pm 34,5^{*}$ & $297,7 \pm 43,4$ \\
\hline \multirow[t]{2}{*}{ АДФ 10, (\%) } & I группа & $66,8 \pm 9,43$ & $63,7 \pm 8,93^{*}$ & $64,9 \pm 7,32$ & $61,7 \pm 6,21$ & $64,7 \pm 6,52$ & $65,6 \pm 8,57$ & $67,1 \pm 9,67$ \\
\hline & II группа & $63,6 \pm 8,65$ & $60,5 \pm 9,65^{*}$ & - & $55,3 \pm 10,6^{*}$ & $59,2 \pm 11,3^{*}$ & $60,9 \pm 8,54^{*}$ & $62,9 \pm 7,6^{*}$ \\
\hline \multirow[t]{2}{*}{ РКМФ, (\%) } & I группа & Пол $21,5 \%$ & Пол 21\% & Пол $22 \%$ & Пол $22,2 \%$ & Пол $23,1 \%$ & Пол $26,5 \%$ & Пол $22,4 \%$ \\
\hline & II группа & Пол 26,7\% & Пол 26\% & - & Пол 28,1\% & Пол 29,3\% & Пол 30,7\% & Пол 26,9\% \\
\hline \multirow[t]{2}{*}{ ПДФ, мкг/л } & I группа & $276,9 \pm 87,2$ & - & - & - & $363,4 \pm 95,3$ & $369,3 \pm 85,6^{*}$ & $268,2 \pm 79,3^{*}$ \\
\hline & II группа & $286,6 \pm 95,3$ & - & - & - & $348,1 \pm 87,3$ & $398,8 \pm 90,8^{*}$ & $253,8 \pm 86,8$ \\
\hline
\end{tabular}

Примечание. Здесь и в табл. $2:^{*}-p<0,05-$ достоверно по сравнению с данными до операции; $* *-p<0,05-$ по сравнению с данными после эксфузии.

Таблица 2

Данные тромбоэластограммы при проведении ОНГ с аутоплазмотрансфузией во время операции кесарева сечения

\begin{tabular}{|c|c|c|c|c|c|c|c|c|}
\hline \multirow{2}{*}{$\begin{array}{l}\text { Показатель } \\
\text { в группах }\end{array}$} & \multirow[t]{2}{*}{ Группа } & \multicolumn{7}{|c|}{ Значения показателей на этапах исследования } \\
\hline & & до ОНГ & после ОНГ & после ТА & после ХГ & после РА & 1-е сутки & 5-е сутки \\
\hline \multirow[t]{2}{*}{$\mathrm{r}+\mathrm{k}, \mathrm{MM}$} & I группа & $22,3 \pm 1,96$ & $24,5 \pm 1,05^{*}$ & $21,9 \pm 1,03^{* *}$ & $24,6 \pm 1,23^{*}$ & $23,9 \pm 1,24$ & $19,1 \pm 1,92^{*}$ & $18,0 \pm 1,93^{*}$ \\
\hline & II группа & $23,5 \pm 1,13$ & $25,6 \pm 1,24^{*}$ & - & $26,8 \pm 1,45^{*}$ & $26,7 \pm 1,29^{*}$ & $21,6 \pm 1,39^{*}$ & $20,1 \pm 1,37^{*}$ \\
\hline \multirow[t]{2}{*}{ ma, мм } & І группа & $47,9 \pm 1,29$ & $47,9 \pm 1,11$ & $45,6 \pm 1,56$ & $44,3 \pm 1,75^{*}$ & $43,1 \pm 1,52 *$ & $44,2 \pm 1,70^{*}$ & $45,2 \pm 1,80$ \\
\hline & II группа & $45,7 \pm 1,64$ & $44,9 \pm 1,14$ & - & $40,2 \pm 1,52^{*}$ & $40,0 \pm 1,18^{*}$ & $42,1 \pm 1,45$ & $44,1 \pm 1,55$ \\
\hline \multirow[t]{2}{*}{ ИТП, усл. ед. } & I группа & $17,9 \pm 1,59$ & $15,5 \pm 1,18^{*}$ & $17,4 \pm 1,67^{* *}$ & $14,8 \pm 1,45^{*}$ & $17,6 \pm 1,38$ & $17,9 \pm 1,51$ & $18,1 \pm 1,39$ \\
\hline & II группа & $18,1 \pm 1,92$ & $16,8 \pm 1,37 *$ & - & $13,4 \pm 1,67^{*}$ & $14,5 \pm 1,27 *$ & $15,6 \pm 1,22^{*}$ & $16,3 \pm 1,86^{*}$ \\
\hline
\end{tabular}

чение ИТП в I группе произошло на $15 \%$ и составило в среднем 17,6 1,38 усл. ед. $(p<0,05)$, тогда как во II группе повышение данного показателя произошло на 8\%, составляя в среднем 14,5 $\pm 1,27$ усл. ед. $(p<0,05)$. Также после возврата аутокрови в обеих группах отмечалось достоверное увеличение количества тромбоцитов в среднем на 12\%: в I группе с $214,7 \pm 24,7$ до $242,9 \pm 44,7 \times 10^{9} /$ л; во II группе - с $203,2 \pm 28,2$ до $228,6 \pm 54,9 \times 10^{9} /$ л. Полученные нами данные совпадают с результатами V. Kretschmer и соавт. (2006), которые утверждают, что при проведении ОНГ во время операции переливание свежей аутокрови обеспечивает поступление в кровоток полноценных тромбоцитов, фибриногена, компенсирующих их потери на гемостаз в операционной ране [7].

Состояние умеренной гиперкоагуляции в I группе вызвано введением активированных факторов свертывания, содержащихся как в аутоплазме, так и в аутокрови. Несмотря на то, что показатели гемостазиограммы во II группе оставались в пределах нормы, при анализе выявлена достоверная разница в результатах между группами, что доказывает наилучший гемостатический эффект применения ОНГ с аутоплазмотрансфузией. Все остальные показатели после реинфузии аутокрови достоверно не изменялись. Полученные нами результаты совпадают с результатами С. А. Кравцова и соавт. (2009), который проводил исследование эффективности острой нормоволемической гемодилюции аутоплазмой при ЭТБС. Автор пришел к выводу, что применение аутологичной свежезамороженной плазмы за счет увеличения концентрации естественных антикоагулянтов, в послеоперационном периоде способствует предотвращению нарастания РКМФ и Д-димеров [8].

На 1-е сутки послеоперационного периода наиболее высокий уровень фибриногена сохранялся в І группе, составляя в среднем 5,04 $\pm 0,92$ г/л, что необходимо для обеспечения адекватного гемостаза после отделения плаценты. Достоверно укорачивался показатель $\mathrm{r}+\mathrm{k}$, составляя в I группе $21,6 \pm 1,28$ мм; во II группе в среднем 19,1 $\pm 1,92$ мм. ИТП достоверно был выше в I группе, составляя в

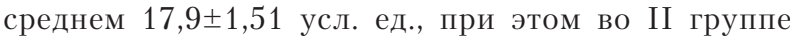


данный показатель составил в среднем 15,6士1,22 усл. ед. Динамика изменений РКМФ в плазме крови, проявляющаяся увеличением данного показателя на 5\%, является не достоверной. Полученные данные во II группе соответствуют нормальным показателям гемостаза раннего послеоперационного периода, которые позволяют предотвратить развитие кровотечения в послеоперационном периоде.

К 5-м суткам послеоперационного периода состояние системы гемостаза в обеих группах характеризовалось умеренной гиперкоагуляцией, характерной для нормального течения послеоперационного периода.

\section{Литература}

1. Ткаченко Р. А. Интенсивная терапия массивной кровопотери в акушерстве. Мед. аспекты здоровья женщины 2010; 2: 29-34.

2. Estella N. M., Berry D. L., Baker B. W. et al. Normovolemic hemodilution before cesarean hysterectomy for placenta percreta. Obstet. Gynecol. 1997; 90 (4 Pt 2): 669-670.

3. Канцалиев Л. Б., Теувов А. А., Базиев А. М. Применение кровесберегающих технологий в абдоминальной хирургии. Хирургия. Журнал им. Н. И. Пирогова 2007; 2: 38-41.

4. Коллинз Ч., Гурунг А. Анестезия при кесаревом сечении. Международный фонд сотрудничества в здравоохранении. Непал. 2008. $1-13$
Выводы

1. Трансфузия аутоплазмы в качестве гемостатического компонента при проведении ОНГ способствует стабилизации коагуляционного потенциала крови и предупреждает развитие гипокоагуляции во время операции кесарева сечения.

2. Аутоплазмотрансфузия расширяет возможности проведения острой нормоволемической гемодилюции при интраоперационной кровопотере объемом до $25 \%$ ОЦК и способствует снижению риска развития геморрагических и посттрансфузионных осложнений в послеоперационном периоде.

5. Серов В. Н., Соколова Ю. Ю., Федорова Т. А. и соавт. Инфузионнотрансфузионная терапия кровопотери в акушерской практике. Акушерство и гинекология 2005; 6: 14-17.

6. Марутян 3.Г., Никифоров Ю. В., Казанщев А. Б., Тер-Григорян А. А. Современные кровесберегающие технологии при реконструкции таза. Общая реаниматология 2010; VI (4): 66-69.

7. Kretschmer $V$. Preoperative autologous blood donation - a`confessor s`point of view. Transfus. Med. Hemotheraol. 2006; 33: 330-335.

8. Кравиов С. А., Власов С. В., Шакурин О. В., Власова И. В. Использование аутоплазмы в профилактике венозных тромбозов при эндопротезировании тазобедренного сустава. Общая реаниматология 2009; V (5): 63-67.

Поступила 18.01.11

\title{
ОБЩАЯ РЕАНИМАТОЛОГИЯ
}

\author{
Научно-практический журнал «Общая реаниматология», \\ входящий в перечень ВАК РФ, предназначен для врачей анестезиологов-реаниматологов \\ и научных сотрудников
}

Тематика журнала: патогенез, клиника, диагностика, лечение, профилактика и патологическая анатомия критических, терминальных и постреанимационных состояний. Вопросы оказания догоспитальной помощи при критических состояниях. Вопросы обучения населения и медицинского персонала приемам оказания неотложной помощи при критических состояниях.

Аудитория: лечебные учреждения; высшие учебные заведения медицинского профиля; медицинские учреждения последипломного образования, Федеральные и региональные органы управления здравоохранением, медицинские научно-исследовательские институты; медицинские библиотеки.

\section{П О Д П И С К А}

\section{В любом почтовом отделении связи по каталогу «Роспечать»}

• индекс 46338 - для индивидуальных подписчиков

• индекс 46339 - для предприятий и организаций 